Diabetologia 10, 193-196 (1974)

(C) by Springer-Verlag 1974

\title{
Glucose Tolerance and Insulin Secretion in Rabbits and Dogs after Ligation of the Pancreatic Ducts
}

\author{
W. Heptner, H.P. Neubauer and R. Schleyerbach \\ Farbwerke Hoechst AG, Pharma Biochemie, Frankfurt, Germany \\ Received: March 22, 1973, and in revised form: January 24, 1974
}

Summary. The present studies on duct ligated dogs and rabbits are an attempt to demonstrate functional alterations in glucose metabolism: 1 . In rabbits the insulin reserve in the pancreatic gland was reduced to about one fifth of its normal value. 2. In dogs, as well as in rabbits, the values of fasting blood glucose remained normal for a period of 12 months following the operation. In rabbits the intragastric, but in dogs both the intragastric and the intravenous glucose tolerance were impaired. 3.
In duct ligated dogs, the increase in serum IRI was diminished after intragastric and i.v. glucose load, as well as after injection of glucagon. Attempts are being made to adapt the model for special studies concerning the early state of diabetes.

Key words: Pancreatic duct ligation, fasting blood glucose, glucose tolerance, serum IRI, effect of glucagon, diabetes model.
It is well known that ligation of the pancreatic ducts results in atrophy and fibrosis of the exocrine pancreatic tissue. Detailed morphological studies $[6,2,19]$ at various intervals after duct ligation in rats have revealed that acinar cells completely disappear within one week and never reappear. The same authors observed some initial damage to the islets, with subsequent regeneration of the islet parenchyma. There is little information about functional alterations, which may follow destruction of the exocrine tissue and degenerative changes within the islets. Goberna et al. [7] observed normal concentrations of IRI and blood glucose during an i.v. glucose tolerance test in rats $3-4$ weeks after duct ligation. 5-7 months after surgery the fasting blood glucose increased to hyperglycaemic values [6]. In dogs, intravenous [11] as well as intragastric [15] glucose loads provoked diabetic blood glucose curves, with normal fasting values.

The present studies were performed to obtain further information about changes of glucose tolerance after the operation. This paper describes comparative experiments on intragastric and intraveneous glucose tolerance tests in normal and duct ligated rabbits and dogs.

\section{Material and Methods}

\section{Animals}

30 mixed bred domestic rabbits, weighing $2.7-$ $3.5 \mathrm{~kg}$, and 20 Beagle dogs, weighing $10-15 \mathrm{~kg}$, were used for these experiments. Normal and duct ligated rabbits were fed with Altromin K (Altrogge, Lage Lippe). Dogs received raw meat and in addition the specific dog food Pal (T) (Fa. Effem GmbH, Verden/Germany).

\section{Operation Technique}

The operation was performed according to Guilian [9], with minor modifications: Following premedication with 1-2 $\mathrm{ml}$ of Combelen (B) (Bayer, Leverkusen, Germany) and $1 \mathrm{ml}(\mathbf{1} \mathrm{mg} / \mathrm{ml})$ of atropine the Beagles were anaesthetized by injection of Nembutal ${ }^{\circledR}$. The anaesthesia was maintained by endotracheal intubation of Halothane (Farbwerke Hoechst, Germany). A midline laparotomy was performed. The possible danger of gut intussusception due to increased peristalsis was prevented by local infiltration of $2 \mathrm{ml}$ $(2 \%)$ of procaine into the tissue surrounding the coeliac plexus. As the pancreas was gently separated from the duodenum the attempt was made to save the supporting mesenteric vessels in order to guarantee optimal blood supply to the gland and duodenum. The pancreatic ducts, in most cases two, were clamped with mosquito forceps and, following double ligation, divided. In order to prevent future adhesions and possible formation of fistulas or accessory ducts a leaf of omentum was wrapped around the duodenum and fixed to it with several interrupted stithes. Closing of the abdomen was accomplished in routine fashion. The post-operative period was usually without any complication. The surgical procedure in rabbits was similar to the one used in dogs. For anaesthesia only Thiogenal (Merck, Darmstadt, Germany) was administered and no infiltration of the coeliac plexus was performed.

\section{Glucose Tolerance and Glucagon Tests}

Glucagon tests were performed 6 months after duct ligation. $50 \mathrm{~g}$ glucose was dissolved in distilled water to make a $100 \mathrm{ml}$ solution. Both dogs and rabbits received $2 \mathrm{~g} / \mathrm{kg}$ intragastrically by means of a stomach tube, and $0.5 \mathrm{mg} / \mathrm{kg}$ by i.v. injection. $1 \mathrm{mg}$ glucagon 
(Farbwerke Hoechst AG, Germany) in $0.6 \mathrm{ml}$ of $0.9 \%$ $\mathrm{NaCl}$ solution was injected into the vena cephalica antibrachii of dogs. Samples of peripheral blood from rabbits (auricular vein) and $1.0 \mathrm{ml}$ blood from the $V$. cephalica antibrachii of dogs were taken at intervals marked in the diagrams.

\section{Analytical Procedures}

Blood glucose was determined by the ferricyanide method using an Auto-Analyzer [10]. Serum IRI was measured radioimmunologically [14] using the test kit of Farbwerke Hoechst, Germany. Insulin was extracted from whole rabbit pancreas according to Randall [16] and measured immunologically against a pig insulin standard as mentioned above.

\section{Results}

The weight of the animals was slightly reduced during 3 weeks following operation, but was reestablished by means of proper diet feeding. Thereafter no significant difference from controls could be observed. Besides some deaths during the operation, no further losses of animals occurred.

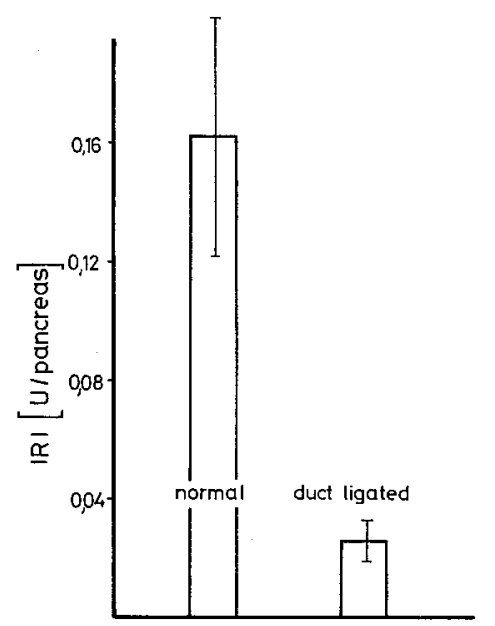

Fig. 1. Comparison of IRI content in total pancreas of duct ligated rabbits and controls after $24 \mathrm{~h}$ starvation. $\mathrm{M} \pm \mathrm{SEM}, \mathrm{n}=6, p<0.05$

\section{Total IRI in Pancreata of Rabbits}

5-6 months after duct ligation the insulin (IRI) content was determined in rabbit pancreas. The animals were sacrificed by i.v. injection of $0.5 \mathrm{ml}$ of T 61 (Farbwerke Hoechst, Germany). This agent is widely used in veterinary medicine for the sacrifice of animals without excitation. Components, are a local anaesthetic, a general anaesthetic and a curare-like compound. The pancreases were removed rapidly. In Fig. 1 IRI content of extracts obtained from whole pancreases of control rabbits and duct ligated animals is compared. The IRI was measured against a pig insulin standard, which may explain the relatively low values. Nevertheless, the results indicate that the insulin reserve is distinctly diminished in the duct ligated animals.

\section{Post-operative Fasting Blood Glucose Levels}

Fig. 2 summarizes the observations on post-operative blood glucose levels after a $24 \mathrm{~h}$ fasting period. In both pancreatic duct ligated dogs and rabbits no changes could be detected compared with control animals.

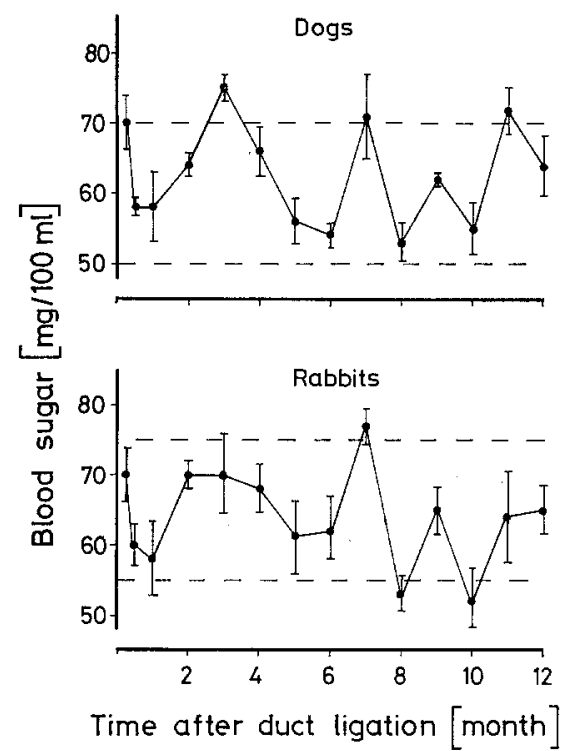

Fig. 2. Postoperative fasting blood glucose in duet ligated animals. $M \pm S E M, n=10$. The lines indicate the range in control animals

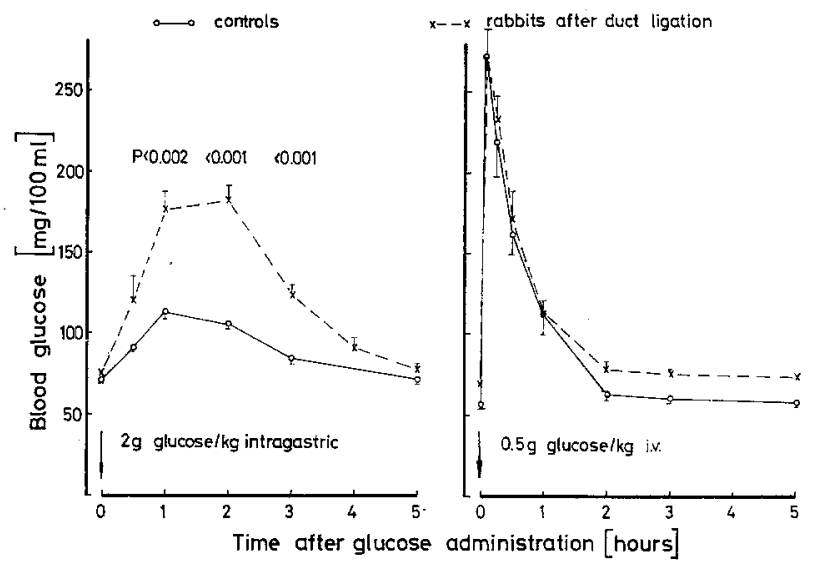

Fig. 3. Comparison of glucose tolerance in duct ligated rabbits and controls. $M \pm S E M, n=15$

Intragastric and Intravenous Glucose Tolerance Tests

Glucose tolerance tests were performed 4-6 months after the operation. The fasting period before 
starting the experiments was $24 \mathrm{~h}$ throughout. The left parts of Fig. 3 and Fig. 4 show blood glucose levels after an intragastric glucose load in controls and duct ligated rabbits and dogs. In the experimental group,
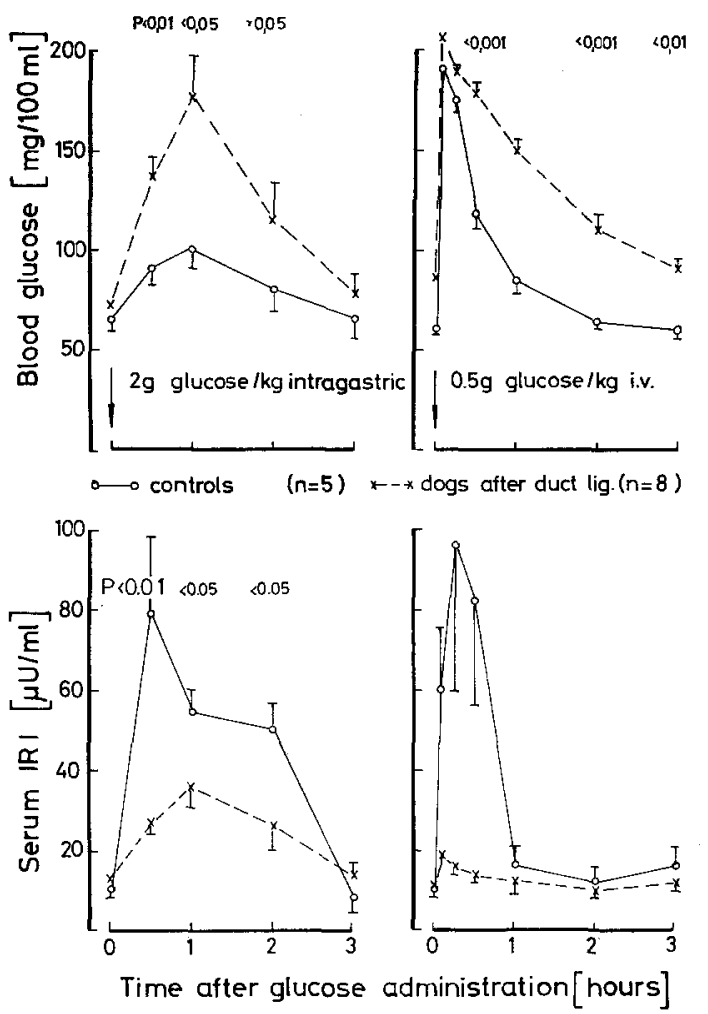

Fig. 4. Blood glucose and serum IRI during intragastric and intravenous glucose tolerance tests in controls and duct ligated dogs. $\mathbf{M} \pm \mathrm{SEM}$

Table 1. Comparison of glucose disappearance in controls and duct ligated animals after injection of $0.5 \mathrm{~g} / \mathrm{kg}$ glucose. $M \pm S E M$

\begin{tabular}{lll}
\hline & \multicolumn{2}{l}{ K-values } \\
\cline { 2 - 3 } & Rabbit & Dog \\
\hline 1. Control & $1.70 \pm 0.13$ & $1.61 \pm 0.22$ \\
2. Duct Lig. & $1.53 \pm 0.15$ & $0.66 \pm 0.05$ \\
\hline
\end{tabular}

trols. In contrast to an intragstric glucose load, there were no differences in the levels of blood glucose after glucose injection to rabbits (Fig. 3). In rabbits the assimilation coefficients, which have been calculated according to Conard [4], were within the normal range. In dogs, however, a significant delay of the decrease of blood sugar levels was observed (Fig. 4, Table 1). Simultaneously, there was a negligible elevation of the basal peripheral serum insulin, whereas the response in normal dogs was in the expected range.

\section{Effect of Glucagon}

A rapid injection of pharmacological doses of glucagon ( $1 \mathrm{mg}$ per dog) caused an immediate rise in serum IRI, with a maximum at three minutes after the application, and a small increase of blood glucose (Fig. 5). In the duct ligated animals insulin response to glucagon was poor. The corresponding blood glucose concentrations were considerably higher than those of the controls.

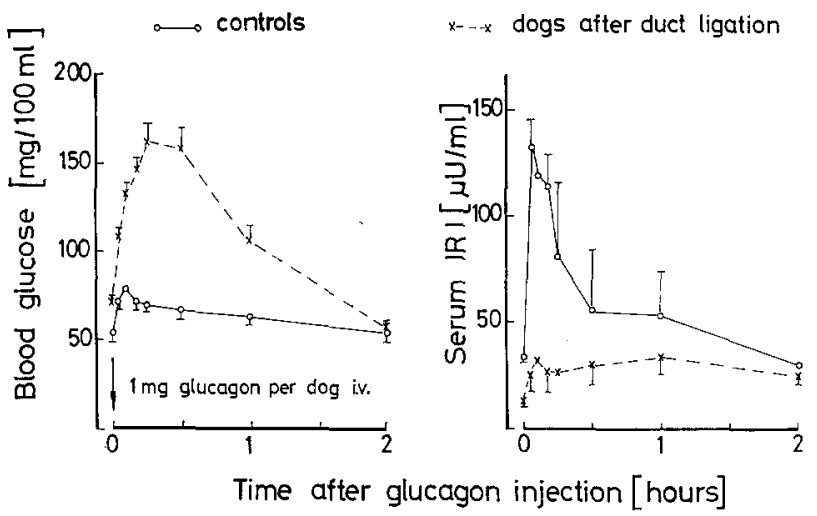

Fig. 5. Effect of glucagon on blood glucose and serum IRI in duct ligated dogs and controls. Animals were fed ad libitum. $\mathrm{M} \pm \mathrm{SEM}, \mathrm{n}=5, p<0.01$ between 3 min and 60 min for blood glucose, and between $3 \mathrm{~min}$ and $20 \mathrm{~min}$ for IRI, respectively

Table 2. Comparison of glucose tolerance in animals with duct ligation

\begin{tabular}{llll}
\hline & Intragastric GT & i.v. GT & Fasting blood glucose \\
\hline Dog & diminished & diminished & normal \\
Rabbit & diminished & normal & normal \\
Rat & normala & normal $(7)$ & normal - increased (6) \\
& & & $0-5 \quad 5-8$ months \\
\hline
\end{tabular}

a Own unpublished observations.

glucose levels reached maximal values of $165 \mathrm{mg} /$ $100 \mathrm{ml}$. As indicated in the diagrams the curves differed significantly from those observed in control animals. In dogs, the corresponding IRI levels were distinctly lower after duct ligation than in the con-

\section{Discussion}

Detailed morphological studies have revealed that duct ligation induces an atrophy of the exocrine pancreas and an initial damage to the islets, with sub- 
sequent regeneration $[2,6,18]$. In dogs, the rapid destruction of exocrine pancreatic tissue $[5,11]$ leads to malabsorption of complex food components i.e.: fat $[15,3]$, proteins [3] and carbohydrates [3], whereas the rate of glucose resorption is not different from that of control animals. In rats, alteration in glucose metabolism, as indicated by normal fasting glucose levels [6], as well as normal kinetics of glucose and IRI during an i.v. GTT [7], could not be observed within the first weeks following the surgery procedure. $5-8$ months after duct ligation the blood glucose rose above normal [6]. In dogs and rabbits, however, fasting blood glucose remained stable during a period of 12 months. Furthermore, dogs developed an abnormal i.v. GTT, but rabbits and rats [7] did not. Little is known about the response of duct ligated animals to an intragastric glucose load. In the literature of animal surgery only a few references indicate a development of a diabetic-like pattern of blood glucose kinetics during an intragastric GTT in dogs $[5,15]$. In our experiments, rabbits and dogs had significantly impaired glucose tolerance following an intragastric glucose load. In both dogs and rabbits the abnormality in glucose tolerance may well be explained by the diminished insulin release after glucose, which leads to significantly lower concentrations of IRI in peripheral blood. The species differences in glucose tolerance are summarized in Table 2.

The question arises whether or not the hypoinsulinism is based upon a reduced insulin content of the pancreas or upon a decreased $\beta$-cytotropic effect of glucose, as well as of glucagon, in duct ligated animals. The results demonstrated in Fig. 1 seem to support the assumption that there is an insufficient reserve of insulin.

Glucagon in pharmacological doses is a potent stimulator of insulin release $[8,13,17]$. The minimal effect of exogenous glucagon upon insulin release in duct ligated dogs allows study of direct actions of this hormone, without interference by insulin. Our in vivo experiments do not support speculations of a disturbed entero-endocrine or exocrine-endocrine pathway [1] after duct ligation. All findings can be interpreted as a consequence of islet cell damage after duct ligation. However, this damage seems to vary from species to species, possibly depending on the capacity of $\beta$-cell replication.

Finally, we should like to recommend this model for the study of certain problems concerning the development of diabetes associated with hypoinsulinism. The surgical procedure is relatively easy, the mild state of diabetes is stable for a long period and is not accompanied by obesity, as it is in most cases of spontaneous diabetes in animals.

Acknowledgements: The authors are indebted to Mirs. Lohfink for skillful technical assistance.

\section{References}

1. Bank, S.: Pancreatic endocrine-exocrine relationships in health and disease. Scand. J. Gastroent. 7, 503-507 (1972)

2. Boquist, L., Edström, C.: Ultrastructure of pancreatic acinar and islet parenchyma in rats at various intervals after duct ligation. Virchows Arch. path. Anat. 349, 69-79 (1970)

3. Coffey, R.J., Mann, F.C., Bollman, J.L.: The influence of the pancreas on the utilization of foodstuffs. Amer. J. dig. Dis. 7, 144-149 (1940)

4. Conard, V.: Mesure de l'assimilation du glucose: base theorique et applications cliniques. Acta gastro-ent. belg. 18, 803-845 (1955)

5. Dragstedt, L.R.: Some physiologic problems in surgery of the pancreas. Ann. Surg. 118, 576-593 (1943)

6. Edström, C., Falkmer, S.: Pancreatic morphology and blood glucose level in rats at various intervals after duct ligation. Virchows Arch. path. Anat. 345, 139$153(1968)$

7. Goberna, R., Fußgänger, R.D., Raptis, S., Telib, M., Pfeiffer, E.F.: The role of exocrine pancreas in the stimulation if insulin secretion by intestinal hormones. Diabetologia 7, 68-72 (1971)

8. Grodsky, G.M., Bennett, L.L., Smith, D.F., Schmid, F.G.: Effect of pulse administration of glucose or glucagon on insulin secretion in vitro. Metabolism $\mathbf{1 6}$, 222 (1967)

9. Guilian, B. B., Mitsouka, H., Mansfield, A.O., Trapnell, J.E., Seddon, J.A., Howard, J.M.: Treatment of pancreatic exocrine insufficiency (II). Ann. Surg. 165, $571-579(1967)$

10. Hajdu, P., Häußler, A.: Modifikation zur Blutzuckerbestimmung mit dem Autoanalyzer. Ärztl. Lab. 8, $274-276(1962)$

11. Idezuki, Y., Goetz, F.C., Lillehei, R.C.: Late effect of pancreatic duct ligation in $\beta$-cell function. Amer. J. Surg. 117, 33-39 (1969)

12. Kief, H.: Unpublished observations

13. Marks, V., Samols, E.: Glucagon mediated insulin release in man. Acta diabet. lat. 5, Suppl. 1, 285-368 (1968)

14. Meade, C.R., Klitgard, H.M. : A simplified method for immuno-assay of human serum insulin. J. nucl. Med. 3, $407-416(1962)$

15. Pairent, F.W., Trapnell, J.E., Howard, J.M.: The treatment of pancreatic exocrine insufficiency. Ann. Surg. 170, 737-746 (1969)

16. Randall, S.S.: The small scale preparation of crystalline insulin. Biochim. biophys. Acta (Amst.) 90, 472476 (1964)

17. Samols, E., Marri, G., Marks, V.: Interrelationship of glucagon, insulin and glucose: The insulinogenic effect of glucagon. Diabetes 15, 855 (1966)

18. Zweens, J., Bouman, P.R.: Neoformation of insulinproducing islets following ligation of the pancreatic ducts in normal and alloxan-diabetic rats. Acta physiol. pharmacol. neerl. 14, 528-529 (1967)

W. Heptner

Pharma Biochemie H 823

Farbwerke Hoechst $A G$

623 Frankfurt 80

Postfach 800320

Federal Republic of Germany 